1. Este artigo toma por base resultados da pesquisa "Arquitetura contemporânea premiada: um estudo de caso: o Prêmio Pritzker", desenvolvida em 2014 com o fomento da FAPESP - Fundação de Amparo à Pesquisa do Estado de São Paulo (processo 2013/25530-2), sob a orientação do Prof. Dr. Ruy Sardinha Lopes, no Instituto de Arquitetura e Urbanismo da Universidade de São Paulo (IAUUSP).

2. Mestranda pelo Programa de Pós-Graduação em Teoria e História da Arquitetura e do Urbanismo do Instituto de Arquitetura e Urbanismo da Universidade de São Paulo (IAU-USP), arquiteta e urbanista.

E-mail: jeseabra@gmail.com.

\title{
DOl: 10.5752/P.2316-1752.2016v23n32p08
}




\title{
O PRÊMIO PRITZKER E A ARQUITETURA CONTEMPORÂNEA PREMIADA'
}

\author{
THE PRITZKER PRIZE ANDTHE AWARD WINNING \\ CONTEMPORARY ARCHITECTURE
}

EL PREMIO PRITZKERY LA AROUITECTURA

CONTEMPORÁNEA PREMIADA

\author{
Jessica Seabra²
}

\section{Resumo}

O crescente vínculo entre cultura e economia aliado à espetacularização do ambiente urbano explicitam nossa total imersão na cultura do dinheiro e implicam a proliferação da cultura do prêmio, tida como uma das alavancas publicitárias essenciais à competitividade internacional de arquitetos e urbanistas bem como dos espaços que criam. Com base no Prêmio Pritzker, este artigo trata do universo dos prêmios como legitimador de cultura arquitetônica e sua influência na criação de um star system da Arquitetura.

Palavras-chave: Arquitetura contemporânea. Prêmio Pritzker. Ambiente urbano.

\begin{abstract}
The growing link between culture and economy associated with the spectacle of the urban environment explains our total immersion in the money culture and imply the proliferation of the award culture. This is considered one of the essential advertising advantages to the international competitiveness of architects and urban planners, as well as the spaces they create. Focusing on the Pritzker Prize, this article deals with the world of awards as an architectural culture legitimizer and its influence in creating a star system of architecture.
\end{abstract}

Keywords: Contemporary architecture. Pritzker Prize. Urban environment.

\begin{abstract}
Resumen
La creciente relación entre la cultura y la economía combinada con la espectacularización del entorno urbano explicita nuestra inmersión total en la cultura del dinero e implica la proliferación de la cultura del premio, considerada una de las palancas publicitaria esenciales a competitividad internacional de arquitectos y planificadores urbanos, así como de los espacios que crean. A partir del Premio Pritzker, este artículo aborda el universo de premios como legitimador de la cultura arquitectónica y su influencia en la creación de un star system de la arquitectura.
\end{abstract}

Palabras-claves: Arquitectura contemporánea. Premio Pritzker. Entorno urbano. 


\section{Introdução}

O costume de atribuir prêmios, medalhas ou troféus culturais (o ato de selecionar indivíduos proeminentes de diversos campos de atuação cultural e lhes galardoar símbolos especiais de reconhecimento) é uma prática ao mesmo tempo habitual, arraigada na sociedade ocidental, e profundamente alienante, visto que premia exceções e não a regra na produção social do espaço.

Suas origens remontam aos concursos de cultura clássicos na Grécia Antiga, onde, no século VI a.C., havia a organização de festivais com competições de poesia, dramaturgia e música, sendo o principal a Grande Dionísia ou Dionísia Urbana, realizado em Atenas (ENGLISH, 2005).

Segundo James English (2005), a criação das academias reais e nacionais de Arte e Literatura, em especial as francesas, fundadas em 1635 e 1649, representou um salto importante não somente na garantia das hierarquias de valor obtidas nos campos da cultura nacional e na conservação ou reforma estética que empreenderam, mas também na consolidação da "cultura do prêmio".

Nesse sentido, é interessante notar como algumas academias surgiram diretamente da ambição de administrar prêmios e controlar o fluxo dos patrocínios, a exemplo da Académie de France em Roma, estabelecida por Charles Le Brun, com o intuito de ali enviar os alunos vencedores dos Grands Prix de Rome. Esses prêmios, os quais a Académie Royale em Paris e sua ramificação em Roma começaram a administrar em 1666, rapidamente se tornaram uma das consagrações mais cobiçadas no mundo europeu da Arte. Graças a esse sucesso, o prêmio foi expandido em 1720 e passou a incluir prêmios de Arquitetura e, no início do século XIX, prêmios em música e gravura (ENGLISH, 2005).

Nesse sentido, o que Le Brun fez foi transformar as academias e os prêmios em uma unidade cultural, parte de uma iniciativa cultural singular, e assegurar os Grand Prix como um circuito institucional fechado, julgado pelos membros da Académie Royale e premiando seus próprios alunos de modo que eles obtivessem mais credenciais acadêmicas de sua instituição satélite (ENGLISH, 2005).

Os Grands Prix apresentam, portanto, duas das principais características dos prêmios verificadas até os dias de hoje: sua dimensão oficial e burocrática e seu desenvolvimento consciente como instrumento de monopolização institucional.

Mais próximo de nós, a criação do Prêmio Nobel de Literatura, em 1901, foi o potencializador dos prêmios culturais modernos. A partir deste, muitos outros começaram a surgir, tanto na área da literatura como em outros campos culturais, incluindo o da música e o da arquitetura, este último objeto deste artigo.

\section{O "modelo" Pritzker}

Fundado em 1979 por Jay A. Pritzker e sua esposa, Cindy, o prêmio Pritzker é financiado pela família Pritzker e considerado o mais prestigiado e conhecido prêmio de Arquitetura do mundo, sendo muitas vezes referido como o "Prêmio Nobel" de Arquitetura. 
A seção "propósito", no website da premiação, apresenta seus objetivos:

Homenagear um arquiteto vivo ou arquitetos cujo trabalho construído demonstre uma combinação das qualidades de talento, visão e compromisso, que produziu contribuições consistentes e significativas para a humanidade e para o ambiente construído através da arte da arquitetura (tradução da autora). ${ }^{3}$

O prêmio não pretende, portanto, ser visionário, identificando novos talentos, mas absolutamente tradicional no sentido de premiar arquitetos com obras consolidadas.

Diego e Pardo (2008, p. 1) apontam que, com a frase "through the art of architecture", presente nos objetivos da premiação e repetida na quase totalidade das menções do júri, o Pritzker se autoencomenda o trabalho de executor e defensor da mais clássica definição de Arquitetura, aquela que a designa como uma das belas-artes, junto à Pintura e à Escultura.

Os ganhadores do Pritzker, ao reafirmar o "estatuto artístico da Arquitetura", restringem os critérios de julgamento aos da arte, a um suposto juízo de gosto. Esvaziam-se, dessa forma, as dimensões política e social da Arquitetura, como enfatiza Pedro Arantes (2010, p. 280):

Não há dúvida de que a reafirmação enfática da arquitetura como Arte mal encobre interesses acintosos de classe. Mas ela tem a grande vantagem de expressar tais interesses no plano elevado da alta cultura, ao mesmo tempo em que consome fundos públicos com obras suntuosas. São premiados os arquitetos capazes de transformar uma dominação dura, material, em uma hegemonia soft.

O Pritzker premia baseado em procedimentos existentes desde a Renascença. A forma de abarcar todas as escolas presentes na lista de laureados pelo Pritzker é a figura do gênio e o imperativo da imagem. Assim como a École de Beaux Arts, o Pritzker premia arquitetos "geniais", que tem na autoria do projeto o seu fator de diferenciação. Na lista dos arquitetos laureados, até mesmo a obra dos arquitetos modernos (que, como o modernismo preconizava, usavam soluções universalistas reproduzidas em grande escala) gravita em torno do culto a suas personalidades.

Mais recentemente, essa personificação se transformou na "produção da exclusividade, da obra única, associada à grife dos projetistas e aos seus patronos" (ARANTES, 2008, p. 179). Essa ruptura aconteceu no Pritzker, de forma radical, em 1989, com a premiação de Frank Gehry, arquiteto que alcançou um inédito patamar industrial de prática projetual amparado por novas tecnologias de modelagem virtual. É o que Pedro Arantes chama de "entrada do projeto na era digital-midiática" e corresponde à passagem da hegemonia do capital industrial para as finanças globalizadas.

As arquiteturas premiadas assumiram então a condição de mercadoria cultural e, como qualquer mercadoria, deviam circular; essa circulação aconteceu como imagem. Em última ins-
3. "To honor a living architect or architects whose built work demonstrates a combination of those qualities of talent, vision, and commitment, which has produced consistent and significant contributions to humanity and the built environment through the art of architecture." Disponível em: <http://www. pritzkerprize.com/about/purpose> Acesso em: 25 out. 2013. 
tância, a própria produção dessas arquiteturas foi comandada pelos ganhos advindos da sua divulgação midiática e da sua capacidade de atrair riquezas, seja por meio de investidores, turistas, captação de fundos públicos, etc. (ARANTES, 2010, p. 2). Daí a relevância do levantamento da obra dos arquitetos premiados em revistas especializadas de Arquitetura, comparando seu comparecimento antes e depois da outorga do Pritzker e outros prêmios de impacto no cenário mundial.

Observa-se nos mecanismos de funcionamento da premiação em estudo a contribuição para a geração de um star system da Arquitetura, no qual as premiações são apenas um elemento. A circulação, o consumo e a distribuição da riqueza da alta arquitetura acontecem ainda na grande mídia, nas revistas especializadas, exposições, concursos. E a legitimação dessa produção se dá pelos críticos de arte, curadores e instituições consagradas de ensino e pesquisa, fechando um ciclo.

A definição de star system para a Astronomia é "um pequeno número de estrelas que orbitam umas às outras" (STAR SYSTEM, 2005). Por associação, star system representa o estrelato arquitetônico, composto por um grupo seleto de arquitetos considerados de elite em termos de produção. Como exemplo, as figuras de Frank Gehry, Zaha Hadid, Norman Foster, Renzo Piano, Richard Rogers, Jean Nouvel, todos laureados com o Pritzker.

Em escala maior, star system também pode se referir a uma intrincada e complexa rede de conexão social na qual a cultura, vista com uma capacidade redentora, é agenciada pelo capital, constituindo-se como a "última trincheira civilizatória do capital" (ARANTES, 2005). Além de arquitetos, essa rede é composta pela mídia, críticos de arte, curadores e até mesmo pelas instituições consagradas de ensino e pesquisa. Isso acontece porque os agentes dessas instituições, assim como jornais e revistas, também circulam, fazendo carreira de um museu a outro, de uma mostra internacional a outra e de uma premiação a outra.

Esse é precisamente o caso do Prêmio Pritzker, que tem, em sua composição, além da família Pritzker como o grande financiadora e dos arquitetos premiados, um júri composto por grupos de interesses. Estes negociam um acordo pelo qual comunicam um conjunto de valores e uma interpretação da produção arquitetônica realizada pelo arquiteto premiado. É o que se desenvolve a seguir, em uma breve análise que se fragmenta em os agentes, o discurso, os recipientes.

\section{O júri}

O júri, encarregado de escolher o laureado do Prêmio Pritzker a cada ano, é formado por especialistas independentes e varia de 5 a 9 membros. Membros antigos permanecem nele por vários anos, e é possível notar na composição do júri uma importante influência das universidades de Harvard e Oxford, onde foi formada ou leciona parte dos jurados e diversos premiados. A estrutura de premiação do Pritzker exibe um círculo praticamente fechado de reforço mútuo entre personalidades 
e instituições, quase todos próximos entre si e integrantes do circuito dos negócios da alta cultura no eixo Londres-Nova York-Boston (ARANTES, 2010, p. 256). Nesse sentido, não se diferenciam muito dos Grands Prix como instrumento de monopolização institucional.

Presididos de 1979 a 2002 por J. Carter Brown, diretor da National Gallery of Art de Washington; em 2003 e 2004 por Lord Rothschild, da National Gallery of Art de Londres; e entre 2005 e 2014 por Lord Palumbo, que já presidiu o Arts Council of Great Britain, LaTate Gallery Foundation e o Arquivo Mies Van der Rohe do MOMA.

Dos júris participam ou participaram:

- diretores, professores, professores convidados e outros profissionais de ensino representantes de Escolas de Arquitetura como Harvard, Oxford, Yale e Rice de Houston; - representantes de importantes museus como o MOMA e a National Gallery da Grã-Bretanha;

- representantes da indústria, como a multinacional norte-americana IBM, na área de tecnologia e consultoria corporativa; a Fiat, uma das maiores fabricantes de automóveis do mundo, com sede na Itália; a Vitra, companhia Suíça de design de móveis; e, mais recentemente, o GrupoTata, um conglomerado industrial localizado em Mumbai, Índia;

- editores de revistas especializadas em Arquitetura, como

a $\mathrm{A}+\mathrm{U}$, críticos e historiadores de Arquitetura; e

- arquitetos renomados, extensamente premiados.

Diego e Pardo (2008) sugerem que da observação da composição do júri nas distintas edições do Pritzker podem-se extrair três cenários que simbolizam três alianças, a saber: 1) Aliança Leste-Oeste; 2) Aliança $1^{\circ}$ Mundo-3 Mundo ou Aliança Ricos-Pobres; e 3) Aliança Global ou Planetária.

Essas alianças estão ligadas ao debate sobre a hegemonia cultural que remete ao Pós-Segunda Guerra Mundial, época em que a identidade norte-americana constrói-se ainda mais fortemente em relação à velha Europa continental, tradicional bastião da cultura ocidental.

Na primeira edição do Pritzker, Philip Johnson foi eleito como pai americano e defensor do Movimento Moderno. A partir daí, o prêmio, como representante da cultura hegemônica ocidental, reorganizou-se na aliança entre Leste e Oeste, presente desde o Pós-Segunda Guerra Mundial, em que os Estados Unidos compartilhava com o Japão a liderança da industrialização e do desenvolvimento. Como representantes da profissão, vemos primeiramente o arquiteto japonês Arata Isozaki no júri, de 1979 a 1984, seguido pelo arquiteto irlandês Kevin Roche, de 1983 a 1991.

A aliança $1^{\circ}$ Mundo- $3^{\circ}$ Mundo está representada na figura do arquiteto mexicano Legorreta, de 1985 a 1993 no júri, e, mais adiante, com Charles Correa, arquiteto indiano, presente no júri de 1993 a 1998.

Diego e Pardo (2008) identificam, em 1989, com a premiação de Frank Ghery, o ano em que questões contemporâneas especialmente ligadas à forma começaram a aparecer no Pritzker. Gehry 

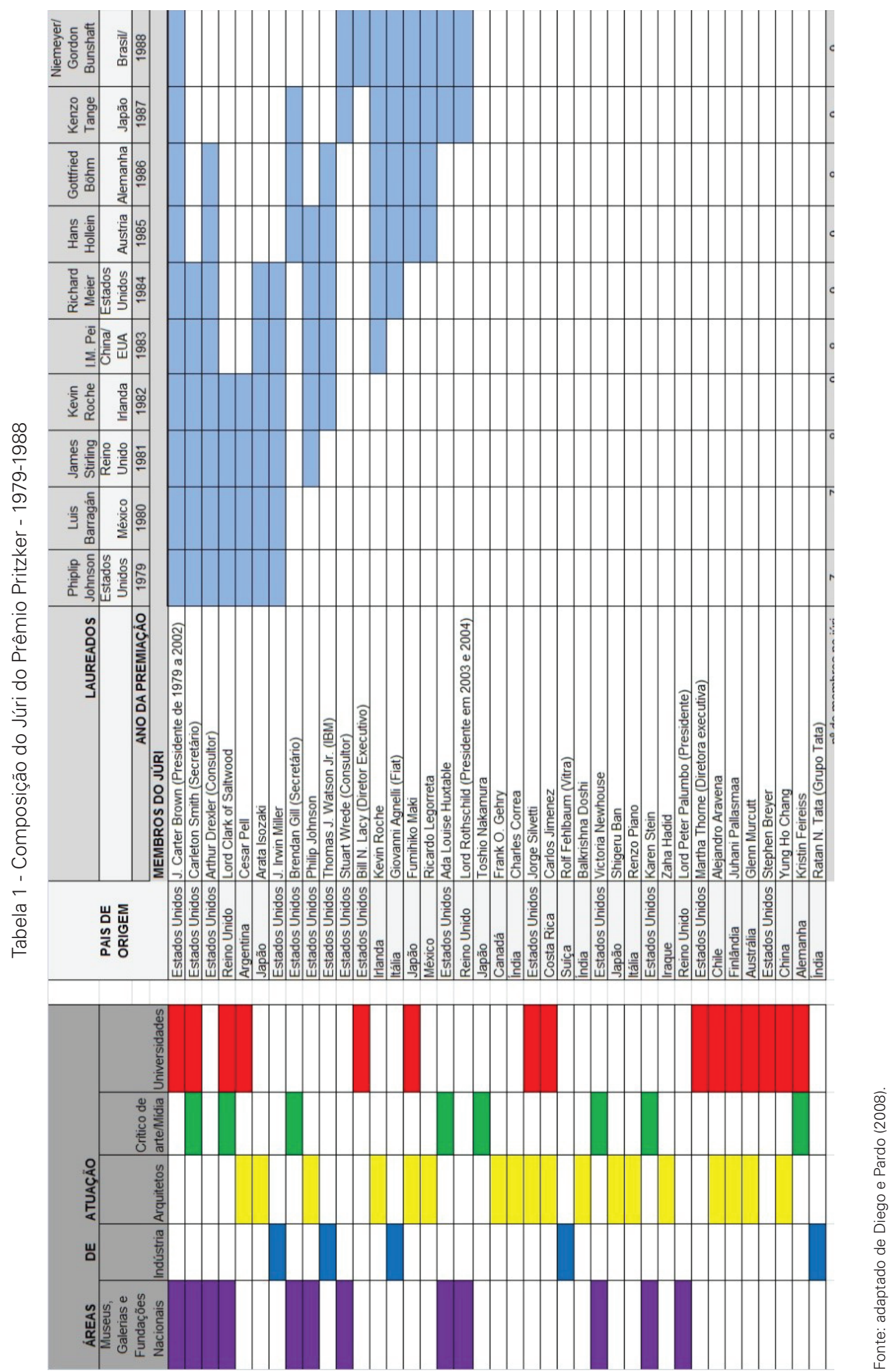

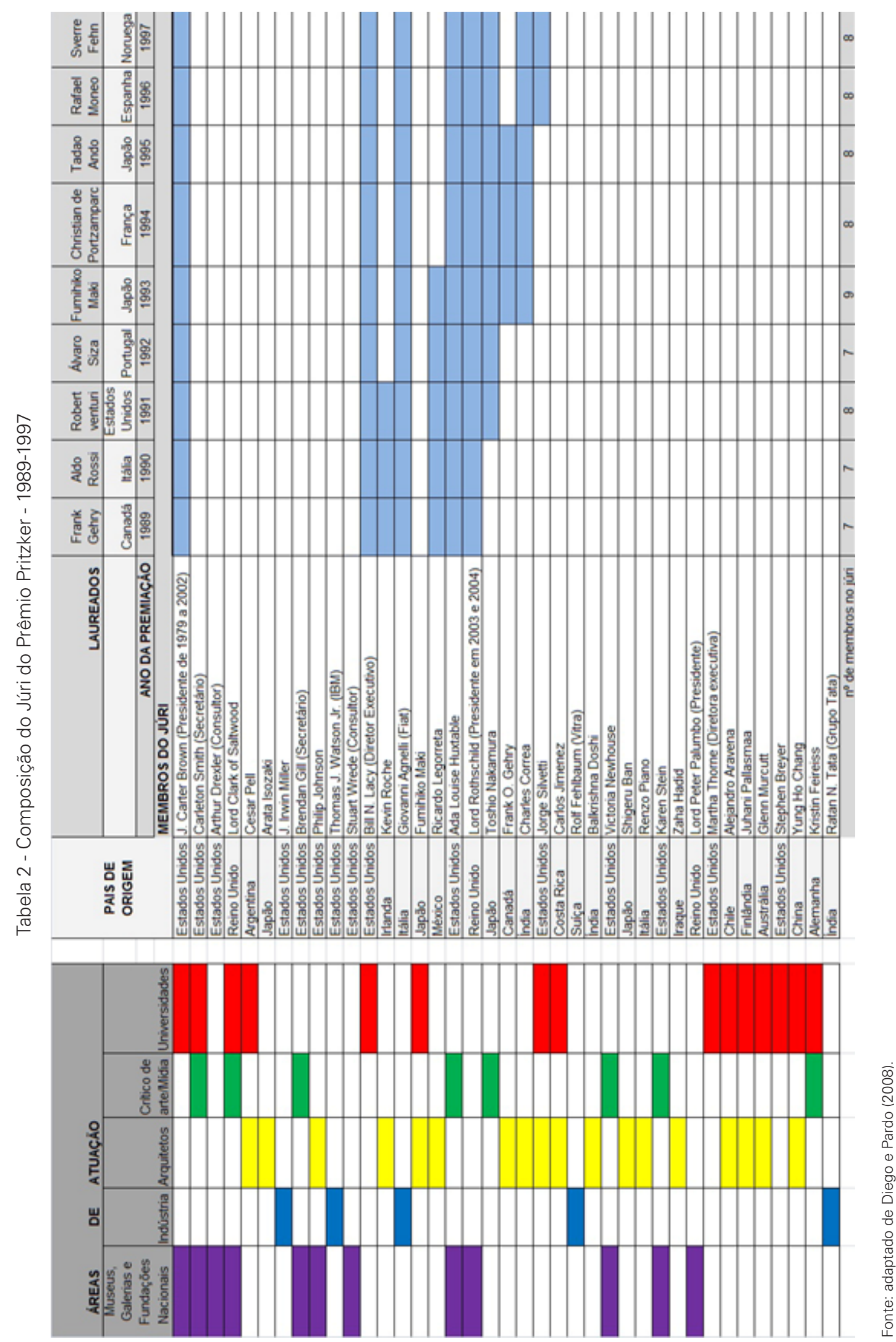

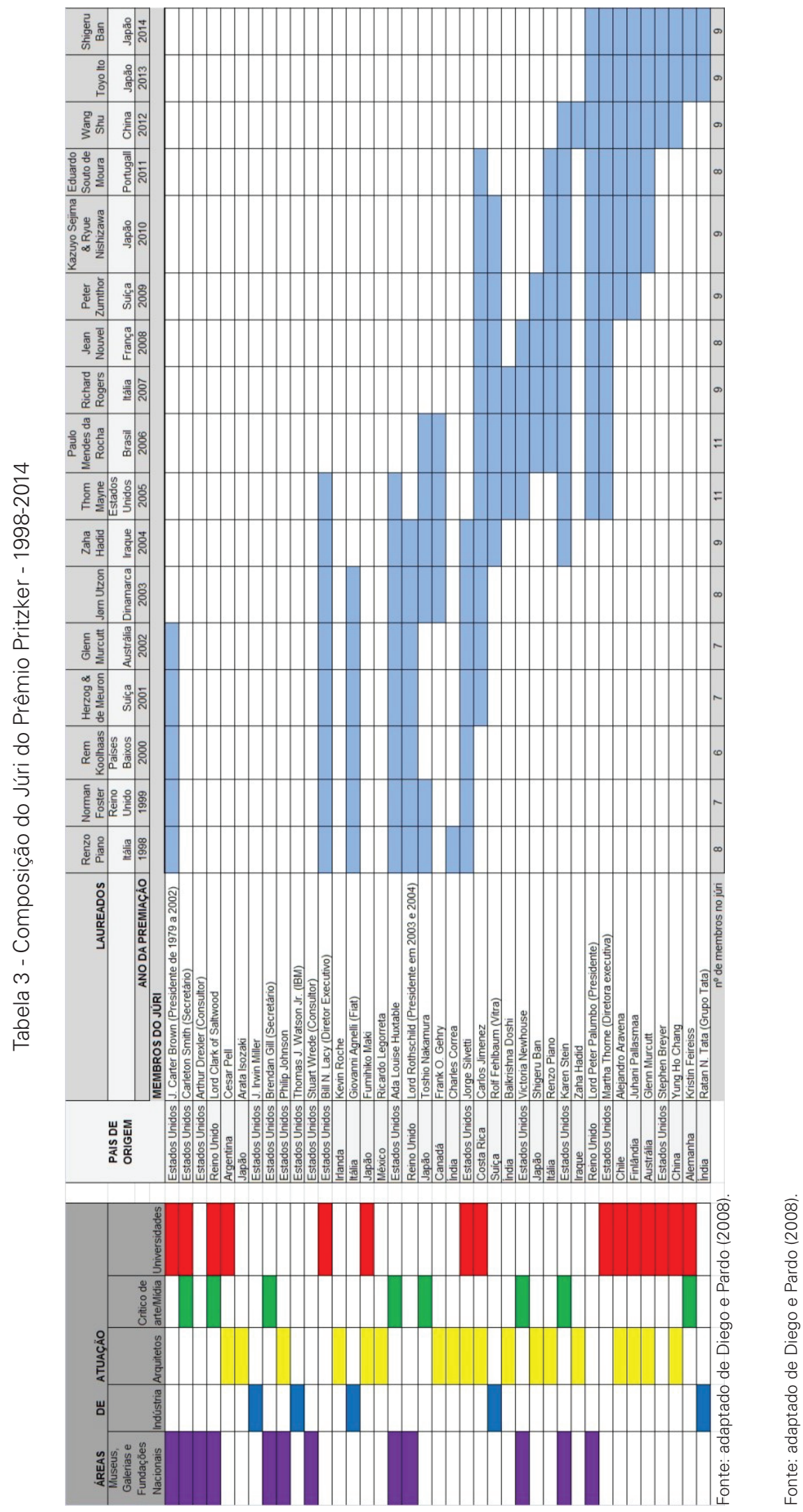
foi considerado o criador de um novo formalismo arquitetônico; com ele, foi revisitada a identidade americana "expressão da sociedade contemporânea e de seus valores ambivalentes."4 Tal período corresponde ao que Pedro Arantes chama de "entrada do projeto na era digital-midiática".

Na citação do júri, a referência a Picasso: "Always open to experimentation, he has as well a sureness and maturity that resists, in the same way that Picasso did".5 Essa mesma comparação foi feita pela crítica de arte americana que elegeu Pollock como emblema de uma arte emancipada da Europa, genuinamente americana (DIEGO; PARDO, 2008, p. 6).

A terceira aliança surgiu apenas em 1998, com a outorga do prêmio a Renzo Piano. De acordo com Diego e Pardo (2008, p. 7), "Na figura dele se fecha um círculo discursivo, ensimesmado na pura visualidade, no valor da arte pela arte e se abre a outros desafios da arquitetura do século XXI". Concordamos com o marco de uma mudança na qualidade da Arquitetura que se premia, entretanto acreditamos que, a partir de então, houve uma correspondência cada vez maior entre os arquitetos premiados e uma prática estetizante e despolitizada na chamada "alta Arquitetura", transformando a Arquitetura em mercadoria cultural. Essa correspondência se inseriu em um momento de mudanças estruturais no regime de acumulação do capitalismo em que economia e cultura se tornavam intrinsecamente ligadas e dizia respeito às teses de Jameson (1996) e Harvey (2007).

A partir da outorga do prêmio a Piano, a premiação pareceu refletir a formação, no campo da Arquitetura, de um "circuito autorreferente da visualidade e do formalismo" (ARANTES, 2010, p. 226). De acordo com Jameson (1996, p. 121), “os edifícios pós-modernos parecem ter sido projetados para serem fotografados". Da mesma forma, as arquiteturas dos premiados a partir de 1998 pareciam concebidas desde o início em razão das imagens que poderiam gerar quando acabadas, e que seriam vendidas a preços de monopólio em virtude de sua suposta originalidade e singularidade.

Os novos desafios do século XXI a que Diego e Pardo se referem comparecem em segundo plano na premiação. Em primeiro plano permanece o posicionamento tradicional da instituição que considera a arquitetura como uma das belas-artes. Termos como "sustentabilidade", "consciência ecológica", "novas tecnologias", "respeito ao lugar", "uso de materiais recicláveis" e "eficiência energética" estão na pauta do Pritzker, assim como na mídia global, mas se revelam apenas como novos ingredientes de uma fuga adiante dentro do mesmo modelo capitalista. Se a crise socioambiental colocou em xeque a lógica de desenvolvimento estabelecida pela sociedade industrial, as empresas e o capital não fizeram mais do que absorver parte do discurso dos movimentos ambientalistas. Com isso, abriram um amplo e novo nicho mercadológico, o do "ecologicamente correto", sem, contudo, alterar os padrões de consumo da sociedade. Tivemos como hipótese que a absorção de um discurso contextualista e ecologicamente correto no Prêmio Pritzker na realidade representa a construção de uma imagem positiva para arquiteturas feitas no sentido de atrair investimentos, inseridas em processos de marketing urbano.
4. Excerto da citação do júri na outorga do Prêmio Pritzker a Frank Gehry. Disponível em: <http://www. pritzkerprize.com/1989/jury>. Acesso em: 21 out. 2014.

5. Excerto da citação do júri na outorga do Prêmio Pritzker a Frank Gehry. Disponível em: <http://www. pritzkerprize.com/1989/jury>. Acesso em: 21 out. 2014. 
Prova disso é que Renzo Piano destaca-se na historiografia da Arquitetura a partir do projeto do Centro Nacional de Arte e Cultura Georges Pompidou, inaugurado em 1977 e elaborado em associação com Richard Rogers. Inspirado pelo movimento high-tech, o Pompidou foi a primeira experiência significativa dessa tendência arquitetônica que compreendia uma combinação de plantas simples, materiais pré-fabricados e uma tendência a expor as estruturas (GHIRARDO, 2002 , p. 258). Dessa forma, as novas tecnologias embasaram a construção de um equipamento cultural de grande porte que foi a âncora no processo de renovação urbana do bairro do Marais, região central de Paris, onde o edifício está localizado. Como tantas outras, a intervenção resultou em processos de gentrificação.

Tomamos para análise, portanto, o período de 1998 (ano da premiação de Renzo Piano) a 2014. A partir das hipóteses investigativas levantadas (institucionalização de novas estratégias projetuais e promoção midiática e mercadológica da "arquitetura de exceção"), foram estudados os 17 arquitetos premiados pelo Pritzker nesse período, verificando a estratégia discursiva da premiação, bem como a inserção da obra dos agraciados nos debates do período.

\section{Os recipientes - arquitetos premiados: os 17 estudados}

Na pesquisa, foram levantados uma série de dados, transformados em gráficos que investigaram e avaliaram qual o papel do Prêmio Pritzker como agente legitimador de cultura arquitetônica. Os gráficos referiam-se a cada um dos arquitetos premiados de 1998 a $2014 .{ }^{6}$ Fez-se o levantamento quantitativo da presença dos arquitetos em questão em três revistas de Arquitetura internacionais, tendo em vista que as publicações especializadas sempre tiveram importante papel no estabelecimento de um debate de conceitos e de ideias em dado meio profissional. No que concerne à Arquitetura, o exame atento de publicações passadas permite a reconstituição (em parte e sempre com o verniz da ideologia do presente, posto que toda narrativa já implica uma seleção) de certo panorama arquitetônico. Dessa forma, esse material foi reunido a fim de entender se o Prêmio Pritzker capta uma tendência já em curso e a reverbera, e, ou, se influencia posteriormente a produção arquitetônica contemporânea e seus meios de reprodução, como as revistas especializadas.

Procurou-se escolher as revistas que exerciam maior influência internacional no período em que os 17 arquitetos em estudo foram premiados pelo Pritzker, de 1998 a 2014, ao mesmo tempo em que foram selecionadas revistas de países que polarizaram os debates de Arquitetura em algum momento da história. São elas a inglesa The Architectural Review, fundada em 1896, a francesa L'Architecture d'Aujourd'Hui, fundada em 1930, e as espanholas Arquitectura Viva, fundada em 1985, esta última representando o grande florescimento da Arquitetura espanhola durante o final da década de 1970 e início da década de 1980, pós-ditadura franquista.
6. A saber, cronologicamente: Renzo Piano, Norman Foster, Rem Koolhaas, Herzog e De Meuron, Glenn Murcutt, Jørn Utzon, Zaha Hadid, Tom Mayne, Paulo Mendes da Rocha, Richard Rogers, Jean Nouvel, Peter Zumthor, Kazuyo Sejima e Ryue Nishizawa - SANAA, Eduardo Souto de Moura, Wang Shu, Toyo Ito, Shigeru Ban. 
Foram feitos também gráficos sobre a produção dos mesmos arquitetos, objetivando mostrar a produtividade dos arquitetos e escritórios (procurando mostrar se a produção cresceu após a outorga de prêmios internacionais), e investigando se houve uma internacionalização da obra antes ou após a outorga do Prêmio Pritzker (a fim de entender se a internacionalização da obra contribui para as causas ou consequências da premiação).

Vale lembrar que os gráficos produzidos têm caráter investigativo e que as premiações são apenas um fator na produção dos arquitetos, em conjunto a fatores econômicos, sociais e também pessoais deles. E, devido à sua extensão, apresentam-se a seguir, não os gráficos, mas uma tabela analítica dos dados levantados.

Tabela 4 - Resumo - Menções dos arquitetos estudados nas revistas, produção dos arquitetos e internacionalização de sua obra antes e após a outorga do Pritzker

\begin{tabular}{|c|c|c|c|c|c|}
\hline Arquitetos & $\begin{array}{c}\text { Architectural } \\
\text { Review }\end{array}$ & $\begin{array}{l}\text { L'arquitecture } \\
\text { d'aujourd'hui }\end{array}$ & $\begin{array}{c}\text { Arquitectura } \\
\text { Viva }\end{array}$ & $\begin{array}{c}\text { Produção } \\
\text { aumentou após o } \\
\text { Pritzker? }\end{array}$ & $\begin{array}{l}\text { Internacionalização } \\
\text { acontece antes (A) e/ou } \\
\text { depois (D) do Pritzker? }\end{array}$ \\
\hline Renzo Piano & 12 & \begin{tabular}{r|r}
1 \\
\end{tabular} & \begin{tabular}{ll|} 
& 2 \\
\end{tabular} & sim & A D \\
\hline Norman Foster & 2 & 1 & 1 & sim & D \\
\hline Rem Koolhaas & 1 & 12 & 12 & sim & A \\
\hline Herzog \& de Meuron & 12 & 1 & 12 & sim & A D \\
\hline Glenn Murcutt & 1 & 1 & 12 & não & não há dados \\
\hline Jorn Utzon & $12 *$ & --------- & 12 & não & A \\
\hline Zaha Hadid & 1 & 12 & 1 & sim & A D \\
\hline Thom Mayne & 2 & 1 & 12 & não & A $\mathrm{D}$ \\
\hline Mendes da Rocha & 1 & 12 & 2 & não & A $\quad D^{* * *}$ \\
\hline Richard Rogers & $1 \quad 2^{*}$ & 1 & 12 & sim & A D \\
\hline Jean Nouvel & $1^{*}$ & 12 & 12 & dados insuficientes & $\mathrm{A}$ \\
\hline Peter Zumthor & 12 & 12 & 12 & não há dados & $\mathrm{D}^{* * *}$ \\
\hline Sejima \& Nishizawa & 1 & 12 & 12 & não há dados & não há dados \\
\hline Souto de Moura & 1 & 12 & 12 & não há dados & $A^{* * *}$ \\
\hline Wang Shu & 2 & $1^{* *}$ & 2 & não há dados & não há dados \\
\hline Toyo Ito & 12 & $1^{* *}$ & 17 & não & $A^{* * *}$ \\
\hline Shigeru Ban & 12 & $1^{* *}$ & 12 & sim & $A^{* * *}$ \\
\hline \multicolumn{6}{|c|}{\begin{tabular}{l|l|l}
$*$ Dados incertos & \\
\end{tabular}} \\
\hline \multicolumn{6}{|c|}{ ** Não há dados para o perío do após a premiação } \\
\hline *** Pouca internacion & lização & & & & \\
\hline
\end{tabular}

Fonte: elaborado pela autora.

A tabela acima resume as análises: o número 1 indica que aquele arquiteto apareceu mais e, ou, com maior número de páginas antes do ano em que o Prêmio Pritzker Ihe foi concedido. O número 2 indica que menções a ele foram mais frequentes no ano de sua premiação e, ou, após. Quando ambos os números aparecem para um arquiteto, significa que ele é citado antes e após a premiação. Quando um número aparece destacado em vermelho e negrito, há um predomínio de menções naquela situação.

Com os levantamentos, pode-se inferir que a quantidade de menções dos arquitetos nas revistas em determinado ano tem
Cadernos de Arquitetura e Urbanismo, v.23, n.32, $1^{0}$ sem. 2016 
a ver com uma equação delicada entre o quanto ele está sendo divulgado no momento por outras plataformas (como as premiações), o quanto ele está produzindo no momento e um perfil editorial da revista.

Com isso, a revista inglesa Arquitectural Review se mostra como a mais constante das três, apresentando obras dos arquitetos antes e após sua premiação pelo Pritzker, com menções e quantidades de páginas bastante equilibradas nas duas fases. A revista francesa L'Arquitecture d'Aujourd'Hui tem uma tendência precursora, apresentando e dando mais ênfase aos arquitetos vários anos antes de sua premiação. E a revista espanhola Arquitectura Viva apresenta os arquitetos antes e após sua premiação e, em vários casos, aumenta o número de páginas dedicadas a eles após sua premiação. Tem com isso um caráter mais midiático, sempre atento ao Pritzker.

A obra de pelo menos 7 dos 17 arquitetos teve saltos de produção após a outorga do prêmio. Os casos em que não ocorre esse aumento são bastante particulares: arquitetos menos midiáticos, que se inserem menos nas revistas, como Paulo Mendes da Rocha, Peter Zumthor, Eduardo Souto de Moura, Wang Shu, Toyo Ito e Glenn Murtutt, ou ainda como Utzon, que pertence a uma geração moderna e cujo auge da carreira aconteceu entre a segunda metade da década de 1940 e o final da década de 1960. Glenn Murcutt inclusive tem outras atividades mais determinantes na sua circulação, como a realização de workshops e palestras em grandes universidades ao redor do mundo.

A obra da maioria dos arquitetos insere-se em países além dos seus de origem e local de trabalho. Entretanto, em pelo menos cinco casos, a internacionalização da obra acentuou-se após a premiação. Uma das características dessa internacionalização dos arquitetos foi a grande presença de países do Oriente Médio e de países emergentes como Singapura, Taiwan, Hong Kong, Coreia do Sul e China, que passam a ser atores importantes no cenário econômico mundial. A grande demanda por projetos de arquitetura na China, por exemplo, presente na obra de alguns arquitetos estudados como KooIhaas (OMA), Herzog e De Meuron, Zaha Hadid e Richard Rogers, parece refletir a média de crescimento real do PIB de 9,5\% entre 1980 e 2004 do país. ${ }^{7}$

Entretanto os arquitetos premiados pelas últimas edições do Pritzker têm a maior parte de suas obras em seus países de origem, corroborando os discursos da premiação, que passam a valorizar uma preocupação com o lugar $^{8}$ e a inserção das arquiteturas nesses lugares. Nas entrelinhas dos discursos de premiação, o júri parece atento ao fato de que interpretar o lugar hoje é uma tarefa complexa que deve ser feita à luz das transformações radicais que a modernidade trouxe à relação entre espaço e tempo, aos mecanismos de sobreposição do global ao local até a simultaneidade proporcionada pelos avanços nos meios de comunicação, transformando as relações dos homens entre si e destes com o meio. Nesse sentido, especialmente a partir da premiação de Zumthor, palavras e expressões como site, local culture, landscape, history, situation se tornaram mais presentes nos discursos do júri.
7. Departamento Nacional de Estatísticas da China. Disponível em: <http://www. frbatlanta.org/pubs/econsouth/05q2portugues_o_crescimento_economico_ da_china.cfm\#chart1 >. Acesso em: 20 out. 2014.

8. O conceito de lugar abrange um vasto campo de discussão nos círculos da crítica arquitetônica contemporânea e estipulou distintas correntes ou vias teóricas de interpretação. Estas vão desde uma interpretação fenomenológica mais imediata, como em Norberg-Schulz, passando por Kenneth Frampton e o regionalismo crítico, até interpretações que se aproximam de considerações sobre a crise contemporânea e suas consequências, como o que concerne às transformações na produção capitalista, a exemplo de Sóla-Morales.

Cadernos de Arquitetura e Urbanismo, v.23, n.32, $1^{0}$ sem. 2016 


\section{O discurso}

Nas citações do júri na outorga dos prêmios a cada edição, há uma notável recorrência das palavras artistic, poet, lyrical, originallity, unique, palette, lasting, creativity, inventive, imagination, tradition, innovator. Esses termos correntes ora associados puramente à arte, ora à alta produtividade, característica das novas tecnologias, estão alinhados, "por assim dizer, à função desbravadora da arte" (ARANTES, 2005, p. 68). Entre eles, "invenção" e "inovação" são:

Termos recorrentes [...] na caracterização do novo manager requerido pela organização dita "em rede" da atual produção capitalista flexível, cada vez mais um profissional que se destacará pelo anticonvencionalismo, pela versatilidade em multiplicar projetos e estabelecer conexões num mundo de negócios cada vez mais relacional (ARANTES, 2005, p. 68).

$\mathrm{O}$ arquiteto premiado pelo Pritzker, transformado em artista, é, como no mundo da alta cultura e no mercado de arte contemporânea, um "especialista em costurar patrocínios e parcerias, e cuja 'arte' foi se transformando num 'produto' de equipe, ou de um 'círculo de qualidade', como se diz no jargão pós-fordista" (ARANTES, 2005, p. 68).

Nos discursos do júri do Pritzker, é possível observar que há também um esforço em balizar características assumidas pela Arquitetura do final do século $X X$, a exemplo da fala do júri na outorga do prêmio a Jean Nouvel, que cita a "manipulação da luz e das camadas transparentes e opacas"9 como temas recorrentes em sua obra.

De fato, essa manipulação que se utiliza das propriedades reflexivas do vidro é recorrente na Arquitetura contemporânea. Se a transparência na Arquitetura moderna era absoluta e tinha como questão a continuidade visual com o entorno, na Arquitetura contemporânea essa transparência é relativa e se traduz na criação de um "plano de delimitação flutuante" decorrente de efeitos visuais variados de evanescência produzidos pela luz nas superfícies. O usuário-observador dessas arquiteturas é colocado em um exercício ambíguo de visão, pois ora tende a coletar a imagem precisa dos objetos ou espaços iluminados e refletidos, ora estabelece relações indefinidas para tentar reter a própria aparência fugaz que Ihe escapa, criando efeitos como a impressão de extensão dos espaços devido à "dissolução" dos limites da forma, até a "desmaterialização" dos corpos sólidos (MUÑOZ; MASSERA, 2010).

Dessa forma, o uso atual extensivo de materiais "transparentes" sugere um novo interesse em um termo que foi, por muito tempo, associado ao movimento de Arquitetura moderna. No entanto, a tensão entre o espectador e objeto implicado pelo uso da fachada arquitetônica como uma membrana indica um descolamento de posturas do passado e uma necessidade de reexaminar a palavra transparência no que se refere à Arquitetura.

É emblemático nesse sentido o projeto para a Tour Sans Fins ("Torre sem Fins"), proposta selecionada como a vencedora
9. Disponível em: <http://www. pritzkerprize.com/2008/jury>. Acesso em: 16 out. 2014

Cadernos de Arquitetura e Urbanismo, v.23, n.32, $1^{0}$ sem. 2016 
para construir um arranha-céu na área de La Defense, em Paris, citado na premiação de Nouvel. Com mais de 400 metros de altura e a intenção de, na época, ser a maior torre da Europa, teve suas fachadas concebidas como uma pele que muda de material (do granito ao alumínio, depois ao aço inox até o vidro), tornando-se cada vez mais claro conforme se aproxima do céu, dando a impressão de desaparecer.

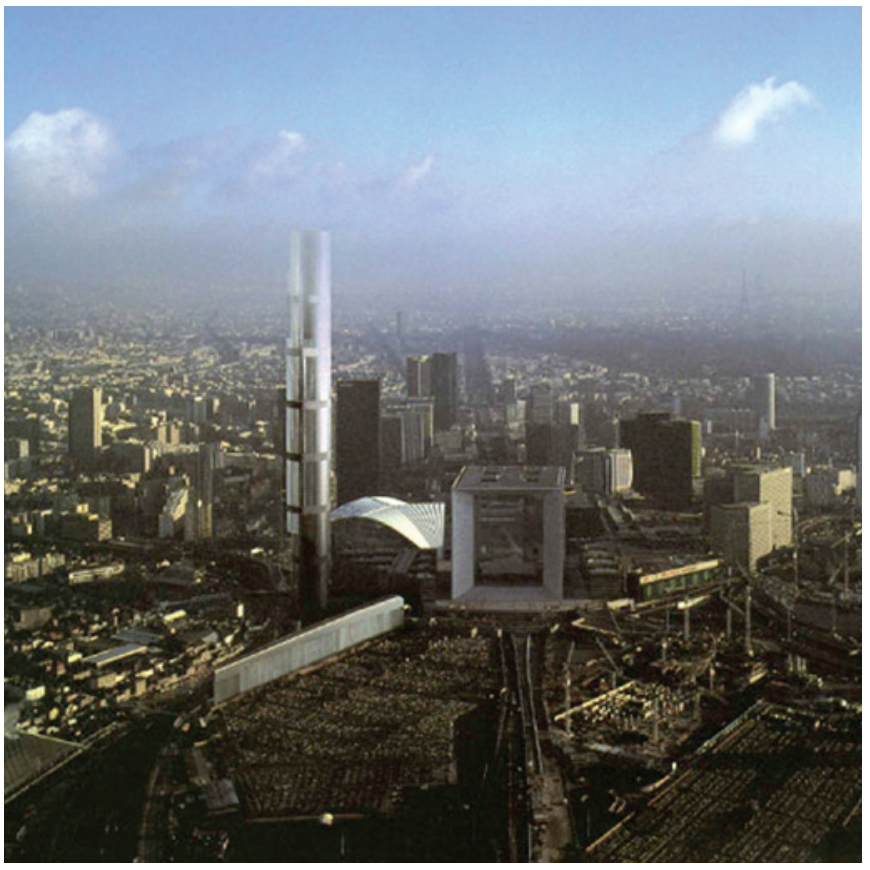

Ainda que em outra medida, até mesmo em arquiteturas mais austeras, a transparência é uma questão fundante. Na Midiateca de Sendai, de Toyo Ito, por exemplo, três fachadas apresentam fechamentos de vidro em toda sua extensão e são concebidas por Ito como uma membrana transparente que permite a comunicação visual do interior com o exterior e que, por vezes, faz com que o limite entre os dois pareça desaparecer.

Além disso, há 13 estruturas tubulares de aço revestidas com vidro, conformando poços de luz que atravessam toda a altura do edifício. Assim, conformam-se dois tipos de iluminação: por um lado, se produz uma luz horizontal massiva e de baixa intensidade que atravessa os planos de vidro das fachadas, refletem-se nas lajes e iluminam os volumes contidos no edifício; por outro, uma luz vertical, focalizada, que se desloca pelo interior dos tubos.

Com isso, cria-se um complexo jogo de luminescências: somam-se os reflexos da luz e as imagens sobre as superfícies dos pavimentos polidos das lajes ao efeito de evanescência dos tubos de aço estruturais que tendem a desaparecer visualmente, e ainda aos efeitos que se produzem sobre as partições, translúcidas e reflexivas, que dividem o espaço interior (MUÑOZ; MASSERA, 2010). Nesse jogo, Toyo Ito tem mesmo como desejo último não criar Arquitetura, o que se reflete na maneira como o edifício está instalado na cidade, apagando os limites entre interior e exterior.
Figura $1 \bullet$ Imagem de projeto da Tour sans Fins em Paris-La Défense, França, projetado entre 1989-1994. Jean Nouvel Arquitetos.

Fonte: Techniques et Architecture, n. 398, out.-nov. 1991, p.92. 


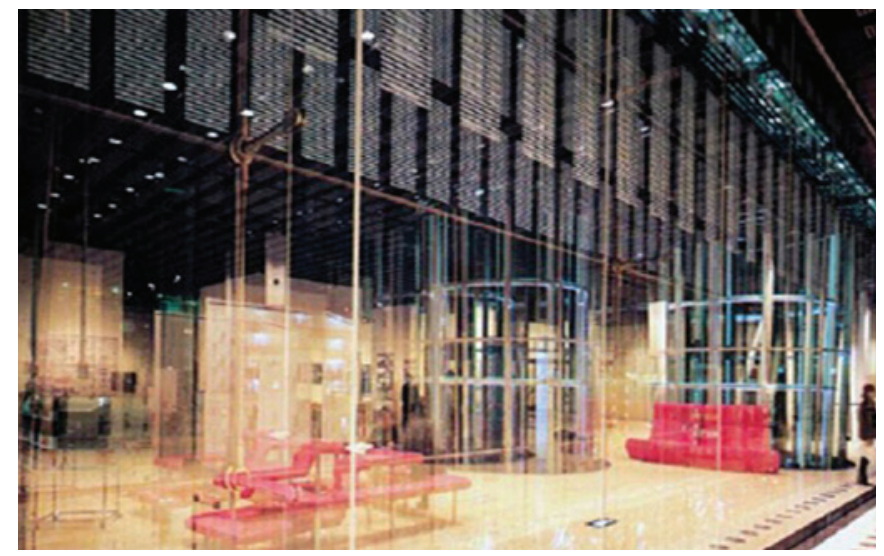

Esse desejo de desmaterialização do objeto arquitetônico parece ser espelho dos tempos, de relações econômicas caracterizadas por mercados e transações financeiras voláteis, em que "sofisticação, técnica ostensiva, diferenciação das superfícies e exuberância formal passam a serem requisitos para constituir imagens arquitetônicas exclusivas" (ARANTES, 2010, p. 2), capazes de materializar o poder e valorizar investimentos.

As obras de Arquitetura, alçadas à condição de mercadoria cultural, parecem atingir um grau inédito de fetichismo. ${ }^{10} \mathrm{Se}-$ gundo Pedro Arantes (2008), a novidade reside na exploração da forma arquitetônica em seus limites materiais, "até a inversão de seus fundamentos construtivos". É nesse sentido que a figura da membrana ou epiderme é recorrente nas obras de arquitetos contemporâneos premiados. A prevalência formal de superfícies em relação à estrutura contribui para a ideia da desmaterialização, ao se impor sobre o volume e a massa de enormes edifícios. A exemplo:

Herzog e De Meuron demonstram ousadia na experimentação de epidermes arquitetônicas cada vez mais inusitadas e imateriais. Passaram de uma experiência de arquitetura mais monolítica, com texturas em pedra, cobre e chapas enferrujadas, para invólucros sempre mais leves e high-tech. Sejam vidros serigrafados e suportados por aranhas metálicas, como na biblioteca de Brandenburgo; placas poliméricas que refratam a luz de forma multicolorida, no centro de dança Laban, em Londres; losangos de vidros côncavos e convexos na Loja Prada de Tóquio; ou as membranas infláveis do Allianz Arena, o estádio de Munique que sediou a abertura da Copa de 2006 (ARANTES, 2010, p. 11).

Reservadas suas diferenças e com qualidades materiais variadas, a epiderme está presente também, por exemplo, no Aeroporto de Barajas, em Madri, ou no Domo do Milênio, ambos de Richard Rogers; no Banco HSBC, de Norman Foster; na Biblioteca de Paris, de Rem Koolhaas, ou em sua torre da CCTV, em Pequim; ou ainda em Zaha Hadid, com seus edifícios que desafiam as categorias usuais arquitetônicas, tratando as volumetrias como intencionais abstrações, como no Centro Heydar Aliyev, no Azerbaijão, no qual uma superfície contínua, que parece homogênea, é, na verdade, formada
Figura 2 • Interior da Midiateca de Sendai, de autoria de Toyo Ito, 2010

Fonte: Sakamoto, 2003, p. 120.

10. Cunhado por Karl Marx, o conceito de "fetichismo da mercadoria" defende que as mercadorias no sistema capitalista ocultam as relações sociais de exploração do trabalho. No contexto da teoria marxista do valor-trabalho, encontra-se no cerne dessas relações sociais a obtenção do lucro por parte de quem detém os meios de produção. Isso acontece porque as mercadorias têm, além do valor de uso, o valor de troca superestimado. O conceito foi ampliado por Adorno e Horkheimer, que observaram a manifestação do fetichismo também dentro da indústria cultural, questão concernente ao sistema capitalista tardio, e combinando, portanto, uma instância distinta da época de Marx. No bem cultural, há uma suposta ausência do valor de uso (que, no entanto, existe e é o valor de uso mediatizado) que acaba reforçando o caráter de troca que o bem cultural tem em uma sociedade capitalista. Outros aspectos sobre o fetichismo incluem "o aperfeiçoamento da mercadoria pela técnica em detrimento do conteúdo; [...] a produção com intuito de ostentar, dissimulando os valores objetivos dos produtos; [...] os 'gadgets' particularizando mercadorias quase idênticas; e [...] a necessidade de consumo 'produzida' pela própria mercadoria, padronizando assim as obras como pretenso resultado das 'necessidades' dos consumidores" (SILVA, 2010). Algo similar está acontecendo com as cidades, impulsionadas a construir arquiteturas espetaculares, convertidas em enormes gadgets, e a sediar eventos a fim de atrair investimentos, competindo entre si.

Cadernos de Arquitetura e Urbanismo, v.23, n.32, $1^{0}$ sem. 2016 


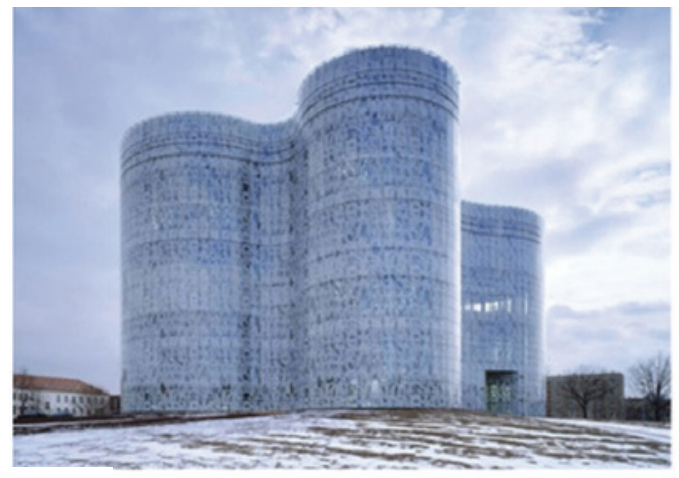

a

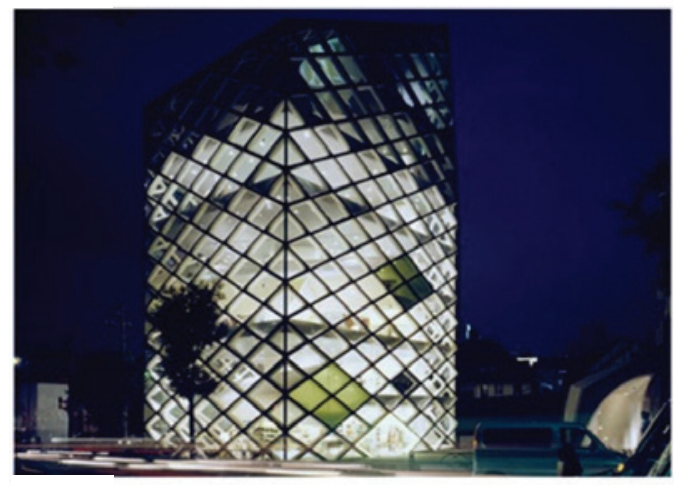

C

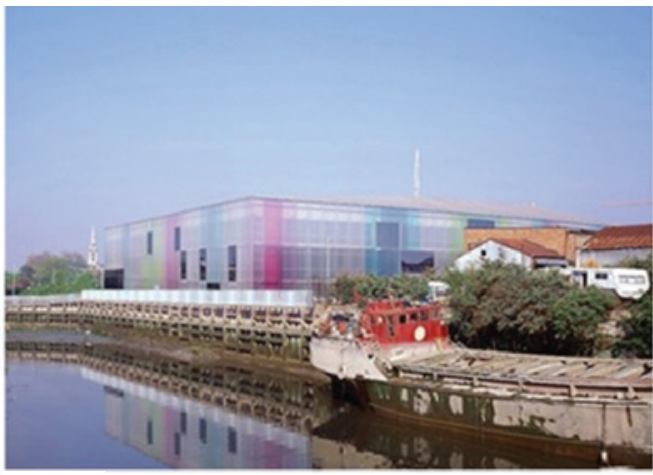

b

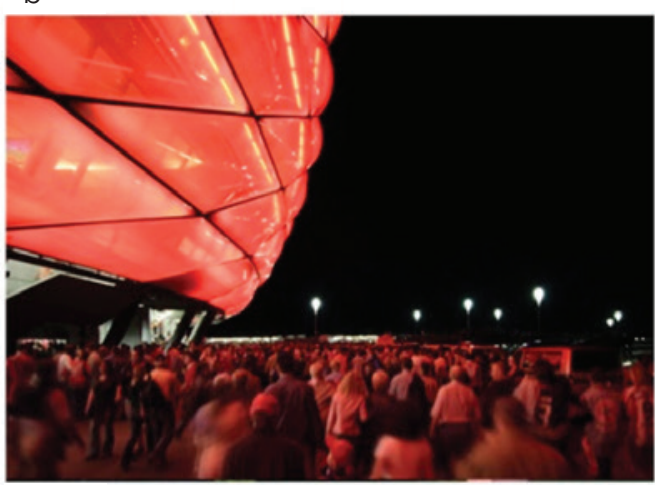

d por uma ampla gama de diferentes lógicas e sistemas construtivos, possibilitados pelo domínio da computação gráfica avançada. A epiderme se tornou uma forma de se posicionar diante das grandes lógicas socioeconômicas mundiais, uma forma de omitir as necessidades programáticas (e, por vezes, também estruturais, como no Centro Heydar Aliyev, de Zaha Hadid) impostas a uma grande estrutura, não revelando o seu funcionamento interno. O exterior oferece um cenário de aparente estabilidade e coerência do todo, e a forma não revela mais a função do edifício.

É bem verdade, entretanto, que, em edições mais recentes do Pritzker, indiretamente tem-se premiado arquiteturas que, ainda que também tenham características monumentais e espetaculares, constituindo-se como edifícios de grande poder simbólico, elas trazem outras questões à premiação, como a preocupação com o lugar e a história, como em Souto de Moura, em cujos projetos a premiação considera que, "na sua aparente simplicidade formal, [...] tecem, juntos, referências complexas às características da região, paisagem, sítio e longa história arquitetônica", criando com isso "espaços que são consistentes tanto com sua história quanto com sua concepção moderna".11

Ou ainda arquiteturas preocupadas com a economia e uso racional dos materiais em relação com questões sociais, como nas últimas três edições do Pritzker, em que a construção de abrigos para vítimas de guerras e de desastres naturais foi destaque: Wang Shu, Toyo Ito e Shigeru Ban, como dito anteriormente. A crise econômica mundial é fator determinante
Figura 3 • a. Biblioteca da Universidade de Brandenburgo de Technology, Cottbus, Alemanha, realizada em 2004;

b. Centro de dança de Laban. Londres, Reino Unido, resultado de competição realizada em 1997, cujo projeto foi desenvolvido entre 1998 e 1999, e construção entre 2000 e 2003;

c. Prada Aoyama em Tóquio, Japão, projetado entre 2000 e 2002, e construção entre 2001 e 2003,

d. Allianz Arena. München-Fröttmaning, Alemanha, resultado de competição realizada entre 2001 e 2002, projetado entre 2002 e 2004, e construção de 2002 a 2005.

Fonte: website dos arquitetos. Imagens disponíveis em: a. <https://www. herzogdemeuron.com/index/projects/ complete-works/151-175/166-cottbuslibrary/IMAGE.html>; b. <https://www. herzogdemeuron.com/index/projects/ complete-works/151-175/160-laban-dancecentre/IMAGE.html>; c. <https://www. herzogdemeuron.com/index/projects/ complete-works/176-200/178-pradaaoyama/IMAGE.html>; d. <https://www herzogdemeuron.com/index/projects/ complete-works/201-225/205-allianz-arena/ IMAGE.html>. Acesso em: 21 maio 2016.

11. Disponível em: <http://www. pritzkerprize.com/laureates/2011/jury>. Acesso em: 15 maio 2015.

Cadernos de Arquitetura e Urbanismo, v.23, n.32, $1^{0}$ sem. 2016 


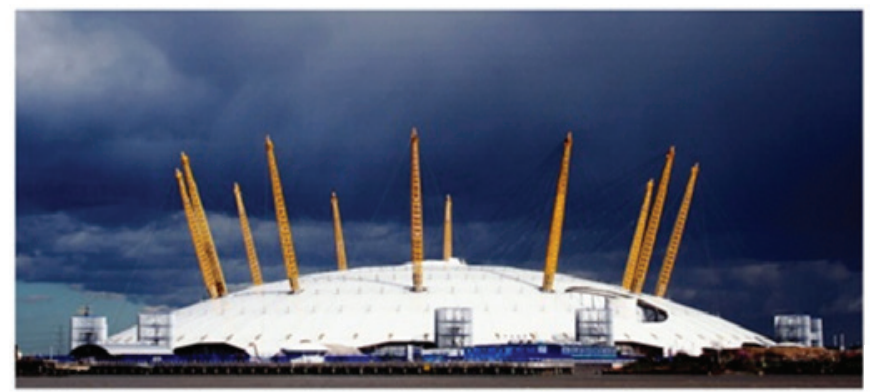

a

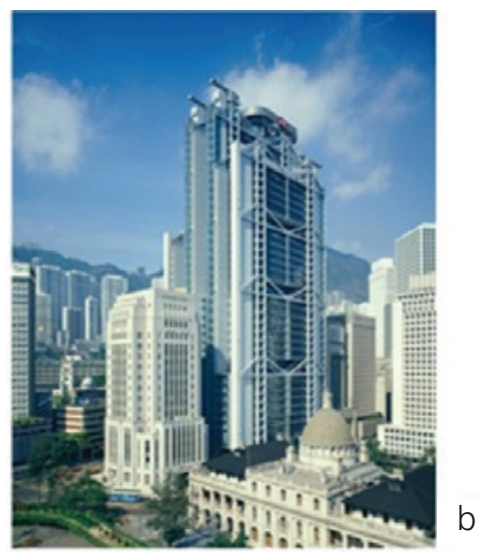

C

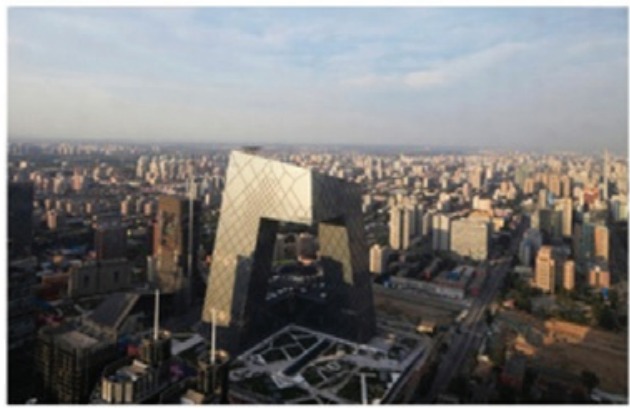

d

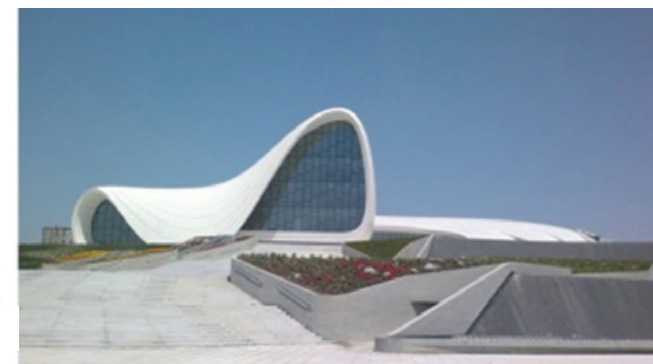

nessa mudança de qualidade, e especialmente de discurso, das arquiteturas que são premiadas.

\section{Considerações finais}

Com base no levantamento da presença dos arquitetos premiados em 17 edições do Pritzker em três revistas de arquitetura internacional e com diferentes perfis editoriais, fica claro que a premiação capta tendências contemporâneas de Arquitetura e as reverbera.

Pode-se perceber que, no recorte estudado, de 1998 a 2014, os discursos do júri realizam uma leitura de uma nova sensibilidade arquitetônica que tem emergido desde meados da segunda metade do século XX. Essa leitura é abrangente no sentido de abordar diversas correntes teóricas que estão já institucionalizadas, a exemplo do desconstrutivismo com Zaha Hadid ou o high-tech com Richard Rogers e Renzo Piano e, em um sentido mais amplo, um desenho contemporâneo permeado pelas novas tecnologias da computação gráfica, a tendência a um desejo de desmaterialização da Arquitetura investido em membranas/epidermes e novos materiais com transparências variadas ou ainda questões como sustentabilidade, economia dos meios, lugar e questões sociais de que a Arquitetura pode ser investida. Por outro lado, essa leitura é limitada ao designar e defender a Arquitetura como uma das belas-artes, inscrevendo a premiação numa chave clássica. Com isso, muitas vezes, realiza elogios pouco críticos à Arquitetura do momento, com enfoque na forma pela forma, sem embasamento histórico ou análise de seus efeitos na sociedade e nas cidades.
Figura $4 \bullet$ a. Domo do Milênio, em Greenwich, Londres, de autoria de Richard Rogers Partnership, projetado entre 1996 e 1999. Foto: Zakgollop, 2006. Fonte: Wikipédia

b. Hongkong and Shanghai Bank Headquarters, em Hong Kong, projetado entre 1979 e 1986 por Norman Foster. Foto: Foster + Partners. Fonte: website do arquiteto.

c. CCTV Headquarters, em Pequim, China, projetado por OMA, 2010. Foto: OMA. Fonte: website do escritório de arquitetos. d. Centro Cultural Heydar Aliev, Azerbaijão, de Zaha Hadid. Foto: Interfase, 2012.

Fonte: Wikipédia. Referências completas das imagens: a. <https://pt.Wikipédia. org/wiki/Ficheiro:Millennium_Dome_ (zakgollop)_version.jpg > ; b. <http://www. fosterandpartners.com/projects/hongkongand-shanghai-bank-headquarters/> c. <http://oma.eu/projects/cctvheadquarters>; d. <https://en.Wikipédia. org/wiki/Heydar_Aliyev_Center\#/media/ File:Heydar_Aliyev_Cultural_Center.jpg >. Acesso em: 21 maio 2016.

Cadernos de Arquitetura e Urbanismo, v.23, n.32, $1^{0}$ sem. 2016 

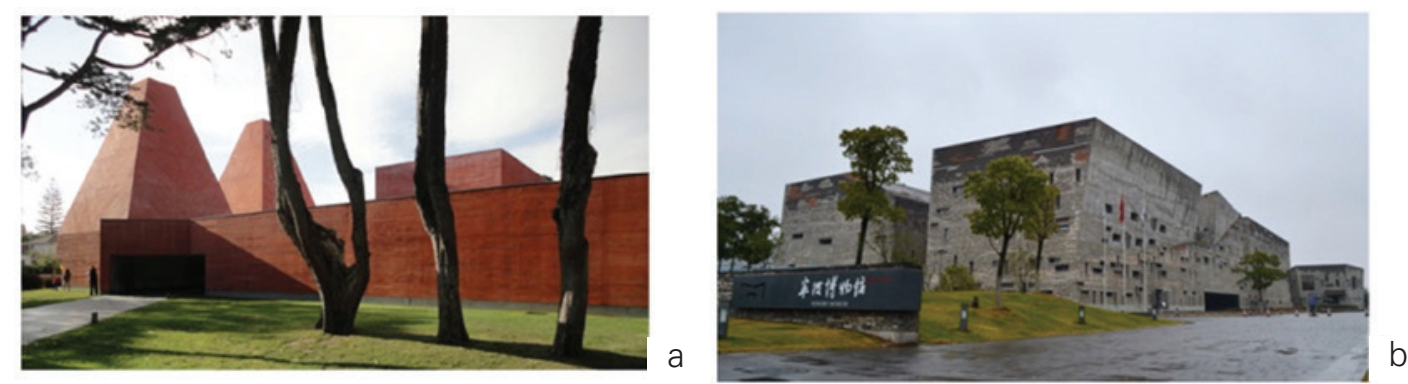

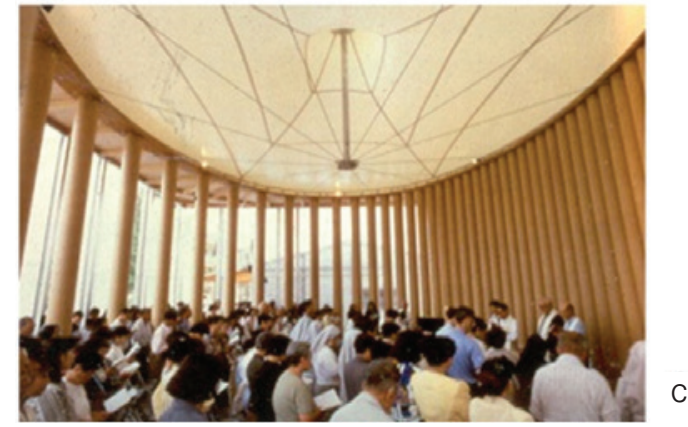

Se, por um lado, não instiga ou promove grandes debates sobre a qualidade da Arquitetura que está sendo premiada, por outro, o Pritzker tem grandes consequências na produção dos arquitetos premiados e nas cidades. Como o mais prestigiado prêmio de Arquitetura internacional, ele legitima uma cultura arquitetônica bastante específica e, em última instância, define e dissemina um padrão de gosto. Isso pode ser comprovado pelo aumento considerável na produção da maioria dos arquitetos após a premiação, além da maior internacionalização de suas obras. E também pela fala de Shigeru Ban, que, ao ser questionado sobre as premiações de arquitetura, ${ }^{12}$ afirma que, após a premiação pelo Pritzker, os arquitetos tendem a ampliar seus escritórios e sua equipe a fim de poder realizar o maior número de projetos que são encomendados.

Shigeru Ban, no entanto, diz que está diminuindo seu escritório para que seu processo de projeto, no qual todas as decisões passam por ele, não mude. Sua postura pode ser distinta, menos midiática, mantendo a produção (assim como Peter Zumthor ou Glenn Murcutt), mas os processos de valorização imobiliária são imediatos, como demonstra uma notícia no The New York Times, ${ }^{13}$ que relata como um apartamento do empreendimento Metal Shutter Houses, assinado por Shigeru Ban, em West Chelsea, em Nova lorque, passou de 5 milhões de dólares em 2009 para 8,5 milhões no início de fevereiro de 2014, logo após a premiação de Ban pelo Pritzker.

A influência do prêmio em um star system é tamanha que hoje o título "vencedor do Prêmio Pritzker" é mais ou menos sinônimo de "star-architect," os arquitetos estrelas, celebrados, midiáticos, que circulam copiosamente na grande mídia, nas revistas especializadas em Arquitetura, na produção das cidades, nessa convergência entre cultura e economia, Arquitetura e Publicidade.
Figura 5 • a. Casa das Histórias Museu Paula Rego, Cascais, Portugal, de autoria de Souto de Moura, 2008. Foto: Manuelvbotelho - Obra do próprio, CC BY-SA 3.0, 2012. Fonte: Wikipédia b. Museu Histórico de Ningbo, de autoria de Wang Shu, 2009. Foto: Siyuwj - Own work, CC BY-SA 3.0, 2012.

Fonte: Wikipédia.

c. Igreja de papel, em Kobe, Japão; obra temporária de Shigeru Ban (1995-2005). Foto: Shigeru Ban Architects.

Fonte: website do arquiteto. Referências completas das imagens: a. <https:// commons.wikimedia.org/w/index. php?curid=21545683>; b. <https:// commons.wikimedia.org/w/index. php?curid=18074335>; c. <http://www. shigerubanarchitects.com/works/1995_ paper-church/index.html>. Acesso em: 21 maio 2016.

12. Shigeru Ban em entrevista no evento "ArqFuturo: A Cidade e a Água", realizado em 23 de setembro de 2014, no Auditório do Ibirapuera, em São Paulo.

13. Disponível em: <http://www. nytimes.com/2014/04/08/nyregion/ interest-in-a-new-york-property-growswith-one-key-addition-a-pritzker-prize. html? partner $=r$ ssnyt\&emc $=r s s \& \_r=3>$ Acesso em: 20 maio 2015.

Cadernos de Arquitetura e Urbanismo, v.23, n.32, $1^{0}$ sem. 2016 

tante. As premiações têm papel importante ao apoiar e celebrar talentos, e suas contribuições à causa da Arquitetura. A crítica maior recai aqui para as ligações intrínsecas entre arquiteturas premiadas e o empreendedorismo urbano, que incorpora estratégias administrativas empresariais e ambos alteram a ordem de funcionamento das políticas públicas em prol de interesses privados.

Muitas das arquiteturas indiretamente premiadas pelo Pritzker estão inseridas em processos e planejamentos estratégicos de cidades que seguem uma lógica orientada pelos imperativos do mercado. Influenciando, assim, direta ou indiretamente, na produção do espaço urbano e agindo diretamente na legitimação de novas políticas urbanas.

Políticas essas que têm tantas vezes sido regidas pela "requalificação" por meio de arquiteturas espetaculares, nas quais as relações sociais urbanas foram substituídas por uma seleção de imagens de arquiteturas cenográficas das quais os indivíduos são meros contempladores. A fórmula do planejamento estratégico gera a expulsão de populações, a gentrificação e uma espécie de teatralização da vida pública, uma vez que os espaços são desvinculados dos residentes e usuários, visto que, constituídos de uma só vez, não consideram as tradições, pessoas e identidades do lugar.

As edições mais recentes do Pritzker se esforçam no sentido de salientar questões sociais da Arquitetura, como a construção de habitação para populações atingidas por desastres naturais, economia de meios e uso racional dos materiais, além de uma preocupação maior com as condicionantes do lugar, seus elementos e tradições. A postura parece surgir devido à crise econômica mundial, que obriga moderações dos excessos econômico habituais da chamada "Arquitetura do espetáculo". Mas, mais uma vez, o Pritzker está captando a tendência: o profissional inovador da vez é aquele preocupado com as soluções ditas sustentáveis e que procura investir o papel da Arquitetura na sociedade com um caráter mais relevante e engajado politicamente.

\section{Referências}

ARANTES, Otília. A "virada cultural" do sistema das artes. Margem Esquerda, São Paulo, n. 6, 62-75, 2005.

ARANTES, Pedro Fiori. Arquitetura na era digital-financeira: desenho, canteiro e renda da forma. 2010. Tese (Doutorado em Tecnologia da Arquitetura) - Faculdade de Arquitetura e Urbanismo, Universidade de São Paulo, São Paulo, 2010. Disponível em: <http://www.teses.usp.br/teses/disponiveis/16/16132/ tde-01062010-095029/>. Acesso em: 24 abr. 2014.

ARANTES, Pedro Fiori. O grau zero da arquitetura na era financeira. Novos Estudos Cebrap, São Paulo, n. 80, p. 175-195, 2008.

DIEGO, Margarita de Luxán García; PARDO, María Jesús Muñoz. Dibujo $Y$ realidad arquitectónica en los premios Pritzker. In: CONGRESO DE EXPRESION GRÁFICA, 12, 2008, Ma- 
drid. Anais... Madri: Escola Técnica Superior de Arquitetura de Madri, 2008. Disponível em: <http://oa.upm.es/21472/2/Dibujo_y_Realidad_en_Pardo_MJ.pdf>. Acesso em: 14 abr. 2014.

ENGLISH, F. James. The economy of prestige: Prizes, awards, and the circulation of cultural value. Cambridge; London: Harvard University Press, 2005.

GHIRARDO, Diane Yvonne. Arquitetura contemporânea: uma história concisa. São Paulo: Martins Fontes, 2002.

HARVEY, David. A condição pós-moderna. 16. ed. São Paulo: Loyola, 2007.

JAMESON, Frederic. Pós-modernismo: a lógica cultural do capitalismo tardio. São Paulo: Ática, 1996.

MUÑOZ, Jaime Arturo Jofré; MASSERA, Carmen Aroztegui. La transparencia y la exclusión: ver pero no estar. Arquiteturarevista, São Leopoldo, v. 6, n. 1, p. 27-36, jan.-jun. 2010. Disponível em: <http://revistas.unisinos.br/index.php/arquitetura/ article/view/4546/1777>. Acesso em: 14 abr. 2014.

SAKAMOTO, T. Sendai Mediatheque. Barcelona: Actar, 2003.

SILVA, Fábio César da. O conceito de fetichismo da mercadoria cultural de T. W. Adorno e M. Horkheimer: uma ampliação do fetichismo marxiano. Kínesis, Marilia, v. 2, n. 3, abr. 2010, p. 375-384. Disponível em: <http://www.marilia.unesp.br/Home/ RevistasEletronicas/Kinesis/FabioCesardaSilva.pdf>. Acesso em: 13 dez. 2014.

STAR SYSTEM. In: BHATIA, A. S. Modern dictionary of astronomy and space technology. New Delhi: Deep \& Deep Publications, 2005.

Recebido em 05/04/2016

Aprovado em 06/05/2016 
Cadernos de Arquitetura e Urbanismo, v.23, n.32, $1^{0}$ sem. 2016 